\title{
A NECESSIDADE DE EXIGÊNCIA DE ESTUDO E RELATÓRIO DE IMPACTO AMBIENTAL SOBRE A CONDIÇÃO LABORAL DAQUELES QUE INTEGRAM A FORÇA PRODUTIVA DO EMPREENDIMENTO
}

\author{
THE NEED FOR STUDY REQUIREMENT AND ENVIRONMENTAL IMPACT REPORT ON THE \\ LABOR CONDITION OF THOSE WHO INTEGRATES THE PRODUCTIVE STRENGTH OF THE
}

ENTERPRISE

Larissa Lopes Matos*

\begin{abstract}
Resumo:
$\mathrm{O}$ artigo busca analisar a possibilidade de se exigir o Estudo de Impacto Ambiental (EIA) e Relatório de Impacto Ambiental (RIMA) no tocante ao meio ambiente do trabalho, notadamente em relação aos aspectos que norteiam a saúde e segurança do trabalhador, para a liberação de atividade empresarial, diante do fato desses instrumentos serem utilizados hoje apenas para avaliar os aspectos relacionados à natureza verde.

Palavras-chave: EIA. RIMA. Direito ambiental do trabalho. Licenciamento.
\end{abstract}

\begin{abstract}
:
The paper seeks to analyze the possibility of requiring the Environmental Impact Study (EIA) and Environmental Impact Report (RIMA) related to the work environment, especially about the aspects that guide the health and safety of the worker, in order to release the business activity, due to the fact that these resources are used today only to evaluate aspects related to green nature.
\end{abstract}

Keywords: EIA. RIMA. Environmental labor law. Licensing.

\section{Importância do tema}

O tema foi pensado diante da realidade fática de que os estudos de impacto ambiental (EIA) e relatórios de impactos ambientais (RIMA) exigidos para liberação de atividade empresarial efetiva ou potencialmente poluidora/degradadora (v.g. licenças de instalação e operação) se restringem somente à natureza verde, ${ }^{1}$ não abrangendo os aspectos concernentes à natureza humana.

Por que a ação do Estado hoje se delimita em avaliar os impactos unicamente sob o prisma dos recursos naturais? A atividade do poder público contemplada na

Doutoranda em Direito pelo Departamento de Direto do Trabalho e da Seguridade Social da Faculdade de Direito da Universidade de São Paulo - USP, e-mail: matos_larissa@usp.br.

1 Para fins didáticos, serão utilizadas no texto as expressões "natureza verde", compreendendo os recursos naturais (v.g. água, solo, flora, fauna) e "natureza humana", para fazer referência ao ser humano. 
legislação se limita a este enfoque? Existe lei regulamentando a imposição de EIA/RIMA em relação à saúde e segurança do trabalhador envolvido na atividade empresarial?

De início, importa observar que é no capitalismo que o hedonismo humano mais se aflora. Se inexistem normas obrigatórias para controlar a atuação das empresas, o capital fará de tudo para potencializar seus lucros e proteger seus interesses a custo do bem-estar dos trabalhadores. Portanto, cabe ao Estado estabelecer os limites para evitar esta relação perniciosa, em nome do interesse público.

Nesse passo, o Estado tem o papel de agente regulador da ordem econômica e agente interventor das questões sociais e liberdades do indivíduo. E para exercê-lo tem poderes, como o poder de polícia, ${ }^{2}$ com a finalidade de ajustar a propriedade e a liberdade do indivíduo aos interesses coletivos.

Por meio do poder de polícia, o Estado impõe finalidades aos indivíduos e empresas privadas que naturalmente (de modo espontâneo) não são desejadas ou perseguidas por eles. O que se busca é solucionar o desafio "obtenção de lucro" versus "inexistência de danos à dignidade da pessoa humana" - em assim sendo, nos países que abraçam o capitalismo, o Estado tem o dever de intervir nas relações privadas para evitar que a busca pelo lucro provoque a exploração do trabalhador, a ofensa a seus direitos e a sua dignidade.

É válido observar que, em regra, as normas contem obrigação de não fazer. Mas quando se trata de poder de polícia, fala-se em obrigação de fazer, com imposições do Estado por meio de leis para controlar a atuação privada das empresas.

Essas leis existem e claramente são aplicadas pelos órgãos ambientais para analisar e liberar licenças de instalação/operação de empreendimentos que impactam nos recursos naturais. Isto é, o exame se dá estritamente em relação à natureza verde. Nesse ponto não há divergência.

Não obstante, o questionamento em tela é sobre a possibilidade de utilizar a mesma legislação para albergar também a análise das condições laborais a que serão submetidos os trabalhadores do empreendimento e, portanto, condicionar as licenças à observância também da legislação de saúde e segurança do trabalho.

É nessa perspectiva que se desenvolverá o estudo, pretendendo-se demonstrar que a legislação ambiental vigente tem um alcance muito mais amplo, viabilizando a atuação do poder de polícia também sob o ângulo da natureza humana, para preservar a sua própria dignidade.

2 Considera-se poder de polícia atividade da administração pública que, limitando ou disciplinando direito, interesse ou liberdade, regula a prática de ato ou abstenção de fato, em razão de interesse público concernente à segurança, à higiene, à ordem, aos costumes, à disciplina da produção e do mercado, ao exercício de atividades econômicas dependentes de concessão ou autorização do Poder Público, à tranquilidade pública ou ao respeito à propriedade e aos direitos individuais ou coletivos (art. 78 do CTN). 


\section{Base principiológica}

O Direito no Brasil tem por princípio basilar a unidade do ordenamento jurídico, cuja Constituição Federal de 1988 é fonte de validade que norteia a interpretação de todas as demais normas jurídicas.

Além disso, no contexto do neoconstitucionalismo, os princípios constitucionais passam a ser vetores de orientação para a interpretação de todas as normas.

Nessa diretriz, o princípio é o "mandamento nuclear de um sistema, verdadeiro alicerce dele, disposição fundamental que se irradia sobre diferentes normas" (MELLO, 1991, p. 299). Enquanto as regras são descritivas da conduta, os princípios são valorativos ou finalísticos (BARROSO, 2003, p. 295).

Outrossim, "princípios são mandamentos de otimização que estabelecem que algo deve ser realizado na maior medida possível, diante das possibilidades fáticas e jurídicas existentes" (ALEXY, 2008, p. 90).

Dessa forma, diante da amplitude da interpretação oriunda de um princípio, deve-se ter cautela para aplicá-lo da melhor forma possível, sem agredir o princípio da segurança jurídica, utilizando-se da técnica da ponderação quando necessária à harmonização entre os princípios constitucionais.

Relacionados ao tema, temos alguns princípios primordiais como: os princípios do direito à sadia qualidade de vida, do desenvolvimento sustentável, da precaução, da prevenção, da melhoria contínua e da informação.

Sobre o princípio do direito à sadia qualidade de vida, a Conferência das Nações Unidas sobre Meio Ambiente, na Declaração de Estocolmo/72, salienta que o homem tem direito fundamental à adequada condição de vida, num meio ambiente de qualidade. Da mesma forma, a Declaração do Rio de Janeiro/92 afirma que o ser humano tem direito a uma vida saudável, segundo Machado (2016).

Direito este que vai ao encontro do princípio do desenvolvimento sustentável, essencial à satisfação das necessidades da geração atual, sem comprometer a capacidade das futuras gerações (equidade intergeracional), sendo necessária, nas lições de Alvarenga (2017), a existência de relação harmônica entre economia e meio ambiente, para assegurar a existência digna para todos, nos termos dos ditames da justiça social (art. 170, VI, da CF/88).

Tal pensamento se concatena igualmente com o princípio da precaução, presente na Declaração do Rio de Janeiro (princípio 15)³ e que na obra de Machado (2016),

3 De modo a proteger o meio ambiente, o princípio da precaução deve ser amplamente observado pelos Estados, de acordo com as suas capacidades. Quando houver ameaça de danos sérios ou irreversíveis, a ausência de absoluta certeza científica não deve ser utilizada como razão para postergar medidas eficazes e 
citando Gerd Winter, possibilita a mitigação dos riscos e, portanto, requer a redução da extensão, da frequência ou da incerteza do dano, mas sem imobilizar as atividades humanas.

Nesse ponto, é interessante fazer uma distinção: o princípio da precaução opera com a perceção de incerteza científica do risco, ao passo que o princípio da prevenção, se alinha à compreensão de certeza científica do dano ambiental (risco conhecido).

Diferenciando didaticamente os princípios da prevenção e precaução, o professor Feliciano aduz:

As noções de prevenção e precaução não se confundem: a prevenção decorre diretamente do texto da Declaração de Estocolmo (1972), podendo ser juridicamente descrita como o mandado de otimização que preordena o impedimento à ocorrência de atentados ao meio ambiente mediante meios apropriados, ditos preventivos (Michel Prieur).

Já o princípio da precaução deita raízes internacionais na Declaração do Rio (1992), consubstanciado no Princípio n. 15, pelo qual "quando houver ameaça de danos sérios ou irreversíveis, a ausência de absoluta certeza científica não deve ser utilizada como razão para postergar medidas eficazes e economicamente viáveis para prevenir a degradação ambiental" (FELICIANO, 2017).

Vale lembrar que nas lições de Machado (2016, p. 120), o princípio da prevenção comporta duas fases: previsão e prevenção. A primeira envolve a fase de colheita de dados e análise, compreendendo o estudo de impacto ambiental; ao passo que a segunda fase abrange a fiscalização e auditoria ambientais, bem como autorizações e licenças ambientais.

O EIA/RIMA e o licenciamento ambiental (art. $9^{\circ}$, III e IV, Lei n. 6.938/81), bem como a necessidade de compatibilizar o desenvolvimento econômico com a utilização racional dos recursos naturais (art. 4º, incisos I e IV, Lei n. 6.938/81), constituem exemplos de aplicação práticas dos princípios da prevenção e da precaução, que levam ao desenvolvimento sustentável e à sadia qualidade de vida, tudo em conformidade com a norma constitucional constante nos arts. $225, \S 1^{\circ}$, IV, e 196, CF, visando sempre o indivíduo - e deste escopo não podemos excluir o trabalhador, que sofre com as intempéries da poluição labor-ambiental.

Sobre a terminologia "poluição labor-ambiental", Maranhão (2017), seguindo a ideia de que a Lei n. 6.938/81 ampliou o conceito de poluição no ordenamento jurídico pátrio, conceitua como o desequilíbrio sistêmico no arranjo das condições de

economicamente viáveis para prevenir a degradação ambiental. 
trabalho com base antrópica, que gera riscos intoleráveis à segurança e à saúde física e mental do ser humano, arrostando-lhe, assim, a sadia qualidade de vida (CF, art. 225, caput).

Além disso, vale lembrar, conforme ensinamentos de Feliciano (2017), que a Convenção OIT n. 155 subministra elenco não exaustivo de objetivos políticos fundamentais à neutralização ou redução dos riscos inerentes ao trabalho e ao local de trabalho.

Relacionado à redução destes riscos ambientais e aperfeiçoamento das condições concernentes à saúde e segurança do trabalhador, não podemos olvidar, segundo lições de Feliciano (2017), o princípio da melhoria contínua, presente no Tratado de Lisboa (art. 114, 1, TFUE), que determina nível de proteção elevado tendo em conta qualquer nova evolução baseada em dados científicos - símile ideia encontramos na NR 15, anexo XIII, item 6.1, ao prever o emprego de todos os esforços na busca de tecnologia mais adequada para evitar a exposição do trabalhador a elementos, como por exemplo, o benzeno.

Tal princípio se coaduna com o princípio da informação, que prega a ideia de ser direito de todo cidadão o acesso às informações necessárias sobre o meio ambiente, compreendido os riscos - nesse sentido é a previsão constante no art. $19, \S 3^{\circ}$, da Lei n. 8.213/91 e art. 19, c, da Convenção n. 155 da OIT.

Esses princípios são essenciais à harmonização das legislações (União, Estados, Distrito Federal e Municípios), interpretação das normas e garantia do direito humano fundamental ao meio ambiente ecologicamente equilibrado (art. 225, CF/88), nele incluído o meio ambiente do trabalho.

Portanto, se relacionam com o escopo primordial do EIA/RIMA que é evitar a degradação do meio ambiente (art. 225, IV, CF/88) e permitir que toda pessoa tenha o direito de desfrutar o mais elevado nível possível de saúde física e mental (art. 121, Decreto n. 591/92 - Pacto de Direitos Econômicos, Sociais e Culturais).

3. Função social da empresa

O Código Civil de 2002 surgiu permeado pelo sistema de normas abertas (cláusulas gerais), parametrizado pela boa-fé e guiado por institutos com função social que valorizam o "ser" em detrimento do "ter".

Assim, no contexto do Culturalismo como matriz filosófica, o referido diploma legal possui três diretrizes fundamentais, trazidas por Miguel Reale, que caracterizam toda a sua sistemática: eticidade, sociabilidade e operabilidade. 
É com base na diretriz da sociabilidade que se impõe ao contrato e a propriedade o cumprimento de sua função social, em observância aos arts. $5^{\circ}$, XXIII e 170, III, todos da CF/88, evitando-se o abuso do direito (art. 187, CC).

Teizen (2017) aborda a relevância da função social da propriedade nas matérias ambientais, ao ponto de se reconhecer inclusive uma função socioambiental da propriedade. Assim, ensina que o direito de propriedade deve ser exercido em consonância com as suas finalidades econômicas e sociais, para se preservar a flora, a fauna, as belezas naturais, o equilíbrio ecológico e o patrimônio histórico e artístico, evitando-se a poluição do ar e das águas, nos termos assegurados pelo art. 225 da CF/88.

Nesse passo, exige-se do contrato de trabalho e do empreendimento o cumprimento de sua função social, sobretudo por terem impactos internos e externos para o trabalhador e para a sociedade, mormente quando descumprem normas de saúde e segurança do trabalho e, consequentemente, contribuem para elevar os níveis de perceção de auxílio-doença, auxílio-acidente, aposentadoria por invalidez e pensão por morte.

Como forma de evitar danos ao meio ambiente do trabalho, bem como preservar a integridade daqueles que integram a força de trabalho do empreendimento e salvaguardar a sociedade de possíveis impactos negativos, faz-se necessária a exigência de EIA/RIMA - a imposição de tais instrumentos é medida compatível com o cumprimento da própria função social da empresa e se coaduna com os art. $5^{\circ}$, XXIII; art. 170, III; e art. 225, todos da CF/88; e art. 157, I e II da CLT.

\section{Conceito de meio ambiente do trabalho}

O meio ambiente é direito fundamental (art. 225, CF/88) de dimensão individual, social e intergeracional, conceituado para os fins previstos na Política Nacional do Meio Ambiente (art. $3^{\circ}$, I, da Lei n. 6.938/81) como "o conjunto de condições, leis, influências e interações de ordem física, química e biológica, que permite, abriga e rege a vida em todas as suas formas", com o fim de proteger o homem e permitir que ele se desenvolva em sua plenitude com qualidade de vida.

Não custa frisar que é o homem o destinatário do direito ao meio ambiente equilibrado, apontado inclusive pela doutrina (FENSTERSEIFER, 2008), na classificação de Karel Vasak, difundida por Noberto Bobbio, como direito fundamental de terceira dimensão ou geração.

Essa compreensão é similarmente destacada por Ingo Sarlet (2003) ao mencionar que o direito ao meio ambiente envolve a figura do homem indivíduo como seu titular, mas também se destina à proteção de grupos humanos e coletividades, tratando, portanto, de um direito de titularidade coletiva ou difusa, que tem como destinatário precípuo o gênero humano. 
Sobre o tema, Supremo Tribunal Federal já se manifestou afirmando que:

$\mathrm{O}$ direito à integridade do meio ambiente - típico direito de terceira geração - constitui prerrogativa jurídica de titularidade coletiva, refletindo, dentro do processo de afirmação dos direitos humanos, a expressão significativa de um poder atribuído, não ao indivíduo identificado em sua singularidade, mas, num sentido verdadeiramente mais abrangente, à própria coletividade social. Enquanto os direitos de primeira geração (direitos civis e políticos) - que compreendem as liberdades clássicas, negativas ou formais - realçam o princípio da liberdade e os direitos de segunda geração (direitos econômicos, sociais e culturais) - que se identificam com as liberdades positivas, reais ou concretas - acentuam o princípio da igualdade, os direitos de terceira geração, que materializam poderes de titularidade coletiva atribuídos genericamente a todas as formações sociais, consagram o princípio da solidariedade e constituem um momento importante no processo de desenvolvimento, expansão e reconhecimento dos direitos humanos, caracterizados, enquanto valores fundamentais indisponíveis, pela nota de uma essencial inexauribilidade (MS 22.164, rel. min. Celso de Mello, j. 30-10-1995, P, DJ de17-11-1995).

Especialmente em relação à definição de meio ambiente, o professor Feliciano (2013) apresenta a noção de Gestalt ao comentar sobre todas as "manifestações particulares da entidade", quais sejam, meio ambiente natural, meio ambiente cultural, meio ambiente artificial e meio ambiente do trabalho.

Dessa forma, oferta-se um sentido condizente com a amplitude do instituto que, muito além dos recursos naturais, incorpora padrões de conduta do homem, envolvendo todo o plexo de suas ações, seja relacionado ao meio digital, à cultura, ao trabalho ou à vida extralaboral.

Por esse ângulo, o conceito de meio ambiente visto a partir da ideia gestaltista não pode ser entendido como algo apenas relacionado à natureza verde (água, solo, ar, fauna, flora), mas sim estudado e definido nos seus aspectos mais globais, inclusive antropológico - sobretudo por tratar-se de conceito jurídico indeterminado que, segundo Fiorillo (2013) cabe ao intérprete o preenchimento do seu conteúdo, com escopo de tutelar o ser humano, pois portador de dignidade (art. $1^{\circ}, \mathrm{III}, \mathrm{CF} / 88$ ) e que possui uma vida não só sob o ponto de vista fisiológico, mas, sobretudo, concebida por valores outros, como os culturais.

Nesta perspectiva é a previsão do art. 191 Constituição do Estado de são Paulo, que explicitamente entabula o conceito de meio ambiente do trabalho: 


\begin{abstract}
Artigo 191 - O Estado e os Municípios providenciarão, com a participação da coletividade, a preservação, conservação, defesa, recuperação e melhoria do meio ambiente natural, artificial e do trabalho, atendidas as peculiaridades regionais e locais e em harmonia com o desenvolvimento social e econômico.
\end{abstract}

Outrossim, o art. 200, VIII, da CF/88 e o art. 223, IV, da Constituição do Estado de são Paulo tem previsão no sentido de que cabe ao Sistema Único de Saúde colaborar na proteção do meio ambiente, nele compreendido o do trabalho - isto é, ambas as Constituições consagram expressamente o "meio ambiente do trabalho".

Por isso, o Professor Maranhão (2017, p. 60) enfatiza

...que a entidade meio ambiente do trabalho não decorre de entusiasmada elucubração acadêmica, tampouco advém de aguerrido ativismo judicial ou mesmo de qualquer diligente performance sindical. Na esfera jurídica, sua autonomia conceitual e seu reconhecimento dogmático estão evidenciados, peremptoriamente, no bojo do mais importante documento de nossa sociedade: a Constituição Federal de 1988.

Sobre o tema, é bom ressaltar que:

A compreensão sobre meio ambiente do trabalho requer forçosamente a determinação do conceito de meio ambiente em geral, na medida em que aquele depende basicamente deste. Por conseguinte, opta-se por um conceito de meio ambiente amplo, que inclua não somente os elementos naturais (água, flora, fauna, ar, ecossistemas, biosfera, recursos genéticos etc.), mas também os componentes ambientais humanos, em outras palavras, o ambiente construído pela ação antrópica (ROCHA, 2002, p. 127).

Além disso, conforme ensina Feliciano (2013), a partir das lições de José Afonso da Silva, "o meio ambiente do trabalho pode ser definido como o local em que se desenrola boa parte da vida do trabalhador, cuja qualidade de vida está, por isso, em íntima dependência da qualidade daquele ambiente".

Seguindo isonômica visão, o professor Maranhão sustenta que:

...juridicamente, meio ambiente do trabalho é a resultante interação sistêmica de fatores naturais, técnicos e psicológicos ligados às condições de trabalho, à organização do trabalho e às relações interpessoais que condiciona a segurança e a saúde física e mental do ser humano exposto a qualquer contexto jurídico-laborativo. (MARANHÃO, 2017, p. 126). 
Portanto, não se pode segmentar a análise do meio ambiente para direcionar a proteção somente a uma de suas faces (natureza verde), quando o objetivo é salvaguardar a sadia qualidade de vida do homem, portador de dignidade e um fim em si mesmo, consoante imperativo categórico kantiano conforme lições de Comparato (2003).

Ainda, é necessário lembrar que a dignidade, como atributo atávico ao ser humano, é noção central do sistema jurídico (art. $1^{\circ}$, III, da CF/88) e tábua axiológica que marca presença no ordenamento pátrio, moldando o tecido normativo infraconstitucional e ofertando parâmetros que condicionam o intérprete e o legislador a prestigiar a ideia que “permita a atuação da vontade constitucional, evitando, no limite do possível, soluções que se refugiem no argumento da não autoaplicabilidade da norma ou na ocorrência de omissão do legislador" (BARROSO, 2015, p. 341).

\section{Estudo de Impacto Ambiental (EIA)/Relatório de Impacto Ambiental (RIMA)}

O estudo de impacto ambiental e seu respectivo relatório são diligências que se realizam previamente à instalação de atividade ou de obra, ou antes da autorização/ licença de funcionamento ou operação, conforme exigência do art. 225, $\S 1^{\circ}$, IV, CF/88.

Importa observar que o EIA/RIMA são instrumentos autônomos ao licenciamento, de acordo com a topografia do art. $9^{\circ}$, III e IV, da Lei n. 6.938/81, sendo este definido pelo art. $2^{\circ}$, I, da LC n. 140/11 como "o procedimento administrativo destinado a licenciar atividades ou empreendimentos utilizadores de recursos ambientais, efetiva ou potencialmente poluidores ou capazes, sob qualquer forma, de causar degradação ambiental".

Inclusive, o licenciamento ambiental apresenta diversos procedimentos, como a possibilidade de realização de audiência pública, com disposição para o público do EIA e RIMA - instrumentos essenciais e prévios aos licenciamentos de empreendimentos causadores de impactos ao meio ambiente.

\section{Para efeitos da Resolução n. 001/86 do CONAMA,}

Considera-se impacto ambiental qualquer alteração das propriedades físicas, químicas e biológicas do meio ambiente, causada por qualquer forma de matéria ou energia resultante das atividades humanas que, direta ou indiretamente, afetam:

I - a saúde, a segurança e o bem-estar da população;

II - as atividades sociais e econômicas;

III - a biota;

IV - as condições estéticas e sanitárias do meio ambiente;

$\mathrm{V}-\mathrm{a}$ qualidade dos recursos ambientais.

Além de aludir ao conceito de licenciamento, a LC n. 140/11 traz como objetivo "garantir o equilíbrio do desenvolvimento socioeconômico com a proteção do 
meio ambiente, observando a dignidade da pessoa humana, a erradicação da pobreza e a redução das desigualdades sociais e regionais" (art. 3º II, LC n. 140/11).

Numa simples conjugação dos incisos I e II da Resolução n. 001/86 do CONAMA com o objetivo constante no art. $3^{\circ}$, II, LC n. 140/11, percebe-se que a legislação demonstra preocupação com a condição de vida do ser humano, sobretudo quando impõe a observação da dignidade da pessoa humana, fundamento constante no art. $1^{\circ}$, III, da CF/88 e vetor de interpretação de normas jurídicas.

Nessa perspectiva, Maranhão (2017) ensina que a degradação da qualidade de vida dos trabalhadores e a degradação do meio ambiente natural são decorrentes de igual contexto socioeconômico, além de apontar que se a noção de meio ambiente escolhida for ampla, assim também será de poluição, pontificando que a poluição ambiental é fato lesivo, antrópico, estrutural, sistêmico, transfronteiriço, transtemporal, intolerável, cultural e plurifacetado.

Portanto, o ser humano que exerce suas atividades no empreendimento também estaria albergado por estas normas, já que sujeito a poluição labor-ambiental, não podendo, consequentemente, ser excluído do alcance dos instrumentos ambientais essenciais à preservação da condição de vida, tais como o EIA/RIMA, sobretudo quando diversos direitos sociais essenciais à vida estão cada vez mais ameaçados pelas políticas econômicas e estratagemas empresariais, relacionadas à superexploração de mão de obra, que visam somente auferir lucros, em detrimento da saúde e segurança do trabalhador e da preservação da sua dignidade.

Nesse passo, condutas contumazes que precarizam o Direito do Trabalho com o mero objetivo de diminuir despesas de mão de obra a qualquer custo, inclusive com reflexos sociais e previdenciários, devem, diante da extrapolação dos limites econômicos e sociais, ser combatidas pelo poder público (no exercício do dirigismo contratual e execução do poder de polícia), preservando-se, sobretudo, o direito de toda pessoa de gozar de condições de trabalho justas e favoráveis (art. $7^{\circ}$, Decreto n. 591/92 - Pacto Internacional sobre Direitos Econômicos, Sociais e Culturais).

Neste ponto, ressalvo que o LTCAT (Laudo Técnico das Condições Ambientais do Trabalho) não substitui os instrumentos em tela, pois a preocupação daquele é averiguar a exposição do trabalhador a determinados riscos ambientais durante o período de permanência na empresa, enquanto o EIA/RIMA buscam evitar a própria existência dos riscos e danos - neste sentido, é bom esclarecer que o PPRA (Programa de Prevenção de Riscos Ambientais) igualmente não substitui os citados recursos, pois este é também exigido após a operação do empreendimento, ao passo que aqueles buscam impedir, previamente, a própria instalação e operação da empresa que não cumpra as normas ambientais. 
Ainda, vale lembrar que o Estado protege os bens jurídicos através de limitações e restrições aos direitos individuais para promover o bem comum. Assim, os cidadãos têm direito constitucional à propriedade (art. $5^{\circ}$, XXII, da Constituição), com atuação livre da empresa, desde que observe os princípios da propriedade privada e sua função social (art. 170, II e III, da CF/88).

Isto é, o direito à propriedade está garantido na medida em que cumpra a sua função social, controlada pelo Estado através de seu poder de polícia. Isso significa que não é permitido o abuso do direito, nem por parte do particular, nem por parte do estado.

No Estado democrático de direito, o uso do poder de polícia se encontra limitado pela Constituição e por sua própria função de manter a ordem pública como condição para o livre exercício das liberdades democráticas, não se permitindo que o exercício da coação de polícia ocorra visando fins distintos dos queridos pelo ordenamento jurídico.

Do mesmo modo, o particular não pode usar de seu bem de forma a prejudicar os direitos do outro, devendo cumprir as normas, cooperar com a ação do Estado e, portanto, implementar as condições inerentes à proteção do trabalhador.

Neste sentido, por meio do poder de polícia, o Estado pode entrar em determinado estabelecimento privado e impor sanções em caso de descumprimento das normas estatais, como as normas de saúde e segurança do trabalhador - diretriz estabelecida no art. 160 da CLT, que aduz se o laudo técnico do serviço competente demonstrar grave e iminente risco para o trabalhador, o Delegado Regional do Trabalho poderá interditar estabelecimento, setor de serviço, máquina ou equipamento, ou embargar obra.

Pelo exposto, o ordenamento jurídico alberga a possibilidade de exigência do EIA/RIMA no tocante ao meio ambiente do trabalho, notadamente em relação aos aspectos que norteiam a saúde e segurança do trabalhador, para a liberação de atividade empresarial, podendo, para tanto, o poder público firmar convênios entre o órgão responsável pela Auditoria Fiscal do Trabalho e os órgãos ambientais com atribuição para licenciamentos ambientais.

\section{Conclusão}

O EIA/RIMA se mostram primordiais à aplicação prática dos princípios da prevenção e da precaução, pois são mecanismos que contribuem para o desenvolvimento sustentável, à sadia qualidade de vida e ao direito humano fundamental de ter um meio ambiente ecologicamente equilibrado, estando inserido nesta ideia o meio ambiente do trabalho. 
Portanto, são instrumentos que podem evitar danos ao meio ambiente do trabalho, bem como preservar a integridade daqueles que compõem a força de trabalho do empreendimento e escudar a sociedade de possíveis impactos negativos, como ocorreu na cidade de Brumadinho - podendo a viabilização ocorrer por meio de convênios entre o órgão responsável pela Auditoria Fiscal do Trabalho e os órgãos ambientais com atribuição para licenciamentos ambientais.

Desta forma, impele-se a propriedade ao cumprimento de sua função social, evitando, assim, grave e iminente risco para o trabalhador, bem como para a sociedade.

Natal-RN, janeiro de 2019.

\section{Referências}

ALEXY, Robert. Teoria dos direitos fundamentais. Tradução de Virgílio Afonso da Silva. São Paulo: Malheiros, 2008.

ALVARENGA, Rúbia Zanotelli de. Princípios fundamentais de direito ambiental do trabalho. In: FELICIANO, Guilherme Guimarães; URIAS, João; MARANHÃO, Ney (coord.). Direito ambiental do trabalho: apontamentos para uma teoria geral. São Paulo: LTr, 2017. v. 3. p. 67-80.

BARROSO, Luís Roberto. Curso de direito constitucional contemporâneo: os conceitos fundamentais e a construção do novo modelo. 5. ed. São Paulo: Saraiva, 2015.

BARROSO, Luís Roberto. O direito constitucional e a efetividade de suas normas: limites e possibilidades da constituição brasileira. 7. ed. atual. Rio de Janeiro: Renovar, 2003.

COMPARATO, Fábio Konder. A afirmação histórica dos direitos humanos. 3. ed. rev. e ampl. São Paulo: Saraiva, 2003.

FELICIANO, Guilherme Guimarães. O meio ambiente do trabalho e a responsabilidade civil patronal: reconhecendo a danosidade sistêmica. In: FELICIANO, Guilherme Guimarães; URIAS, João (coord.). Direito ambiental do trabalho: apontamentos para uma teoria geral. São Paulo: LTr, 2013. v. 1. p. 11-25.

FELICIANO, Guilherme Guimarães. Tutela inibitória em matéria labor-ambiental. Revista do Tribunal Superior do Trabalho, Brasília, v. 77, n. 4, p. 140-161, out./dez., 2011. Disponível em: https://juslaboris.tst.jus.br/bitstream/handle/1939/28338/005_feliciano.pdf?sequence=5. Acesso em: 2 maio 2017.

FELICIANO, Guilherme Guimarães; ARAÚJO JÚNIOR, Francisco Milton. Direito comunitário europeu e tutela jurídica da saúde e segurança no meio ambiente do trabalho. In: FELICIANO, Guilherme Guimarães; URIAS, João; MARANHÃO, Ney (coord.). Direito ambiental do trabalho: apontamentos para uma teoria geral. São Paulo: LTr, 2017. v. 3. p. 13-26. 
FENSTERSEIFER, Tiago. Direitos fundamentais e proteção do ambiente: a dimensão ecológica da dignidade humana no marco jurídico-constitucional do Estado socioambiental de direito. Porto Alegre: Livraria do Advogado, 2008.

FIORILlO, Celso Antonio Pacheco. Curso de direito ambiental brasileiro. 14. ed. rev. ampl. e atual. São Paulo: Saraiva, 2013.

MACHADO, Paulo Affonso Leme. Direito ambiental brasileiro. 24. ed. São Paulo: Malheiros, 2016.

MARANHÃO, Ney Stany Morais. Poluição labor-ambiental: abordagem conceitual da degradação das condições de trabalho, da organização do trabalho e das relações interpessoais travadas no contexto laborativo. Rio de Janeiro: Lumen Juris, 2017.

MELLO, Celso Antônio Bandeira de. Elementos de direito administrativo. 2. ed. rev. ampl. e atual. com a constituição federal de 1988. São Paulo: Revista dos Tribunais, 1991.

ROCHA, Julio Cesar de Sá da. Direito ambiental do trabalho: mudanças de paradigma na tutela jurídica à saúde do trabalhador. São Paulo: LTr, 2002.

SÃO PAULO. [Constituição (1989)]. Constituição do Estado de São Paulo. São Paulo, out. 1989. http://www.pge.sp.gov.br/centrodeestudos/bibliotecavirtual/dh/volume\%20i/constituicao\%20 estadual.htm. Acesso em: 12 jan. 2019.

SARLET, Ingo Wolfgang. A eficácia dos direitos fundamentais. 3. ed. rev., atual. e ampl. Porto Alegre: Livraria do Advogado, 2003.

TEIZEN, Thaís. Princípio da socialidade: a responsabilidade social em face dos direitos difusos e coletivos. Ambito Jurídico, Rio Grande, XVII, n. 125, jun. 2014. Disponível em: http://www. ambito-juridico.com.br/site/?n_link=revista_artigos_leitura\&artigo_id=14809. Acesso em: 23 abr. 2017. 
